\title{
A flood-risk-oriented, dynamic protection motivation framework to explain risk reduction behaviours
}

\author{
Philippe Weyrich $^{1}$, Elena Mondino ${ }^{2,3}$, Marco Borga ${ }^{4}$, Giuliano Di Baldassarre ${ }^{2,3}$, Anthony Patt ${ }^{1}$, and Anna Scolobig \\ ${ }^{1}$ Climate Policy Group, Department of Environmental Systems Science, Swiss Federal Institute \\ of Technology (ETH Zurich), 8092 Zurich, Switzerland \\ ${ }^{2}$ Department of Earth Sciences, Uppsala University, 75236 Uppsala, Sweden \\ ${ }^{3}$ Centre of Natural Hazards and Disaster Science, Uppsala, Sweden \\ ${ }^{4}$ Department of Land, Environment, Agriculture and Forestry, University of Padua, 35122 Padua, Italy \\ ${ }^{5}$ Environmental Governance and Territorial Development Hub/Institute, University of Geneva, 1205 Geneva, Switzerland
}

Correspondence: Philippe Weyrich (philippe.weyrich@usys.ethz.ch)

Received: 15 April 2019 - Discussion started: 23 April 2019

Revised: 2 December 2019 - Accepted: 12 December 2019 - Published: 23 January 2020

\begin{abstract}
Private risk reduction behaviours can significantly reduce the negative impacts of flooding and flash floods. Over the past decades, researchers have used various sociocognitive models or threat and coping mechanisms to explain individual protective behaviours. However, these models ignore the fact that people are not equally ready to act upon a danger, and they (the models) give limited insights into the effectiveness of communication strategies to foster risk reduction behaviours. Therefore, we explored the current state of homeowners' readiness to undertake risk reduction behaviours in flood risk areas by applying a dynamic protection motivation framework. We conducted a survey in an Italian municipality that experienced severe flash flooding in September 2018. The results show that people are motivated by different factors in prompting risk reduction behaviour based on their chosen types of protective measures. For example, people that undertook structural or avoidance measures are more likely to be motivated to protect themselves by increased perceptions of vulnerability and response efficacy and are less worried about expected flood losses compared to people that undertook only basic emergency measures. In this paper, we argue how these new insights contribute to targeting flood risk communication strategies to groups of individuals characterized by different readiness stages and motivations to protect themselves.
\end{abstract}

\section{Introduction}

Flooding and flash floods are major causes of naturalhazards-related deaths; they affect the lives and safety of millions of people worldwide (Guha-Sapir et al., 2017; Kellens et al., 2013). In 2017 alone, 345 flood events killed 6500 people and caused economic losses of USD 42.5 billion (Munich RE, 2017). With climate change influencing extreme weather events, more people will likely be exposed to higher flood risk in the near future than they are at present. For example, most cities worldwide are projected to experience an increase in precipitation rates in the form of heavy rainfall (IPCC, 2012). The high proportion of sealed surfaces further increases flood risk (Carter, 2011), and the concentration of people, assets and critical infrastructure, as well as political and economic activities, exacerbates the impacts of extreme events (European Environment Agency, 2017). Hence, the protection of livelihoods from flood events as an adaptation strategy to climate change will be of high priority in the coming years. Different types of adaptation to flood risk exist. For social systems one can differentiate between administrative and private adaptation, as well as between reactive adaptation during a flood and precautionary adaptation before a flood (Grothmann and Reusswig, 2006). Given similar exposure and sensitivity to floods (that, along with adaptation, determine flood damage and vulnerability), private protective action can have significant effects on flood outcomes as it was documented, for instance in Grothmann and 
Reusswig (2006). Risk reduction behaviours include structural measures (e.g. special installation of heating and electric systems, anti-backflow valves), avoidance measures (e.g. keeping valuables and expensive appliances above floodprone areas of the house), and emergency preparedness (e.g. own sandbags available, emergency plan at hand).

The adoption of risk reduction measures plays a critical role in the transition from top-down to people-centred approaches for disaster risk management. Authorities and public officials highlight the importance of people protecting themselves and see sharing responsibility as an appropriate form of response (Bostrom et al., 2015; Box et al., 2013; Morss et al., 2015; Scolobig et al., 2015). However, it remains unclear whether this actually matches the capacity of individuals to increase their levels of protection (Scolobig et al., 2015). For instance, in the case of floods, citizens often transfer the responsibility for their own safety and protection to the agencies in charge (Adger et al., 2013; Bichard and Kazmierczak, 2012). This may be related to the fact that people perceive flooding as a human-made phenomenon rather than a natural one, for example in the Mediterranean region (Diakakis et al., 2018; Lara et al., 2010). This clearly reveals that one of the key challenges in the transition to peoplecentred approaches is the responsibility shift from the authorities to the public, demanding that the latter take precautionary actions (Scolobig et al., 2015). In the face of this change, it is important to investigate the current readiness of individuals to undertake risk reduction behaviours and to identify the triggers that influence individuals to act.

So far, researchers have used socio-cognitive models to explain risk reduction behaviours (Grothmann and Patt, 2005; Grothmann and Reusswig, 2006). The most important factors used in these models are risk perception, hazard experience, risk aversion and socio-demographics. The influence of coping mechanisms was highlighted in studies that followed the protection motivation theory (PMT; Kellens et al., 2013; Poussin et al., 2014). More recently, the role of insurance and public assistance on private risk reduction behaviour has been investigated (Hanger et al., 2018). These models all have in common that they assume that people are equally ready to act upon danger, and they give limited insights into the effectiveness of communication strategies to foster risk reduction behaviour. However, the public is no homogeneous group (Martens et al., 2009). Some people might be ready to take responsibility and act to reduce their flood risk exposure, while others adopt different behaviours. Thus, there are different stages or degrees of readiness which can influence individual motivation and intention to protect themselves from a risk (Horwath, 1999; Prochaska et al., 1995). In the transtheoretical model (TTM), people are assigned to one of several stages based on their behaviours and intentions to undertake risk reduction actions (Prochaska et al., 1995). For example, Horwath (1999) addressed the question of whether eating behavioural change follows a stage process that could be used to help nutritionists to identify the pre- dominant stages in a population. Enhanced knowledge about these stages allows for the focus of resources on the issues that will most likely move people to the next stage. In medical research, Block and Keller (1998) showed that people are at different stages of readiness to undergo medical testing, which can be affected by cognitive processes.

In this study, we focus on the drivers of risk reduction behaviours, employing a dynamic framework that combines the protection motivation theory (PMT) and the transtheoretical model (TTM). The aim of this study is twofold. First, we aim to determine the usefulness of this dynamic protection motivation framework to understand people's perceptions of flood risk (i.e. to be affected in their home) and their readiness to undertake risk reduction behaviours. Second, we aim to identify the most important factors in prompting behaviours in different risk reduction stages. Combining PMT with TTM will help to deal with the non-homogeneity of the population, which is not equally ready to adopt protective actions, and to better understand the respective motivations in order to reduce some of the uncertainty in predicting flood risk behaviour. This framework allows us to further identify the key issues to improve communication with people in each stage. Thus, we contribute to targeting flood risk communication strategies to groups of individuals characterized by different readiness stages and motivations to protect themselves.

\section{Background}

Flood management has shifted from a primarily top-down, command-and-control approach to an integrated approach that increasingly addresses the role of private households in implementing flood damage mitigation measures (Kellens et al., 2013; Terpstra and Gutteling, 2008). To foster this transition, there is a need to integrate the analysis of residents' risk perceptions and preparedness into local flood risk management practices (Figueiredo et al., 2009). The majority of studies have focussed on flood risk perceptions, for instance via the effect of past experience and effect (Keller et al., 2006; Siegrist and Gutscher, 2006, 2008) or as a means to explain and promote private protective behaviours (Kellens et al., 2013). However, this is not always supported on theoretical or empirical grounds as Kellens et al. (2013) document; higher risk perceptions alone do not necessarily lead to a positive change in protective behaviour. For example, Siegrist and Gutscher (2006) found that even though people living in areas with higher levels of designated risk had higher risk perceptions than people living in areas of no flood risk, there was no difference in prevention behaviour between the groups. Other studies that were conducted in flooding areas documented an overall low level of preparedness and observed no relationship between risk perception and preparedness (Diakakis et al., 2018; Kreibich et al., 2005; Takao et al., 2004). Likewise, Scolobig et al. (2012) found no link between residents' levels of risk awareness and preparedness. 
Wachinger et al. (2013) found that high risk perceptions (predominantly shaped by personal experience and trust) do not lead to risk reduction behaviours if people accept the risk (i.e. benefits outweigh costs), if they do not feel responsible or if they have few resources. Other recent studies highlight instead that protective behaviours are influenced not only by high risk perceptions but also by high coping appraisal (a person's perceived ability to cope with and avoid being harmed by a threat in an effective way; Bubeck et al., 2012; Kellens et al., 2013; Parker et al., 2009). These results, in part contradictory, show that it is important not only to focus on flood risk perception as the main driver of risk reduction behaviour but also to understand other factors that might trigger individuals to protect themselves from a hazard.

Protection motivation theory (PMT) has quite often been applied to the natural-hazards and public-health sectors (Floyd et al., 2000; Maddux and Rogers, 1983). According to PMT, people can be motivated to engage in desirable behaviours to avoid risks (Floyd et al., 2000). The theory consists of two sequential underlying cognitive mediating processes, the threat-appraisal process and the copingappraisal process, whereas assessments of threats (perceived risk severity, vulnerability and benefits) and coping factors (self-efficacy, response efficacy and costs) combine to form a motivation in individuals to adopt protective behaviours. Several studies have applied the PMT to flood risk and analysed its influence on people's risk reduction behaviour. Grothmann and Reusswig (2006) identified that both threat and coping appraisal determined people's adaptation behaviours to increased flood risk in the past (e.g. construction of structural measures, acquisition of protection devices). They conclude that practitioners should communicate not only the flood risk and its impacts but also the possibility, effectiveness and cost of risk reduction behaviours. Zaalberg et al. (2009) found a significant effect of response efficacy (defined as the degree to which risk reduction behaviours are perceived to be effective at reducing a particular risk) on behavioural intention but no effect of self-efficacy (defined as the belief that one is capable or not in undertaking risk reduction measures) on behaviour. Finally, Poussin et al. (2014) found that, while threat appraisals had only a small effect on people's intentions to implement flood risk mitigation measures, coping appraisal had a more important influence.

However, PMT does not consider that the public is heterogeneous and may be differently affected by variables of vulnerability, severity and ability to reduce the risk (Martin et al., 2007). A parallel stream of research in decision stage theories has been used to examine behaviour change based on the assumption that a set of variables, such as from PMT, will influence different people in different ways (Horwath, 1999). The transtheoretical model (TTM) specifies an ordered set of categories into which people are classified (Martin et al., 2007). Based on this categorization, one can identify the factors (e.g. response efficacy) that can explain how to effectively communicate with each subgroup (i.e. in a specific decision stage; Weinstein, 1998). The three decision stages which are frequently used in empirical studies are pre-contemplation, contemplation and action. The baseline premise is that people can be distinguished based on those who have not yet decided to change their behaviour (precontemplation), those who have (contemplation) and those already performing the new behaviour (action; Martin et al., 2007). Thus, TTM stages are sequential and can change through time.

In consequence, an integrated PMT-TTM model offers the possibility of investigating risk information and perception dimensions and stage readiness for action, thus allowing us to predict individuals' motivations to act upon the hazard. The PMT-TTM model was introduced by Block and Keller (1998) in a health-related context and more recently applied by researchers (Bočkarjova et al., 2009; Gebrehiwot and Veen, 2015; Martin et al., 2007) in the natural-hazards context. In these three studies, respondents were grouped in different decision stages based on the amount of suggested protective measures that had already been undertaken. Martin et al. (2007) investigated the role of motivation, decision stages of risk readiness and subjective knowledge on the number of risk-mitigating actions undertaken by homeowners living in areas exposed to high wildfire risks in the US. Independent of knowledge and decision stage, they found that all PMT variables were negatively correlated with taking risk reduction behaviours. The authors ignored the two PMT variables costs and benefits, as well as other control variables. Bočkarjova et al. (2009) analysed the cognitive perception of flood risk and the readiness of people to undertake protective actions in the Netherlands. Overall, they showed a significant influence of response efficacy and costs on risk reduction measures. The authors used an extended model which also considered other variables and found an influence of subjective knowledge, trust in government and experience on behaviours. Gebrehiwot and Veen (2015) applied the PMT-TTM framework to areas of drought risk in a developing-countries cultural context (i.e. smallholder farmers in Ethiopia). For the whole sample, they found that vulnerability, severity, self-efficacy and response efficacy are positively correlated and costs negatively correlated with action-taking.

However, it cannot be ignored that there is ambiguity in their findings. The studies do not agree with respect to which PMT variable(s) (vulnerability, severity, benefits, response efficacy, self-efficacy and costs) influences behavioural intention in the different decision stages. Moreover, differences also exist in their methodological set-up, and their models differ (e.g. including costs and benefits as PMT variables or not). These differences could have an important effect as, for example, Wachinger et al. (2013) highlighted that perceived benefits and costs can influence individuals' decisions to act upon a risk or not. In addition, Bubeck et al. (2012) argued that a possible feedback from previously adopted protective measures could change risk perceptions. This is in 
line with findings highlighting that individual expectations of government responses shape the public's actions in response to floods and longer-term adaptation (Adger et al., 2013; Chamlee-Wright and Storr, 2010). Public adaptation and damage compensation can lead to reduced private protective behaviour either because citizens view flood mitigation as a government responsibility (Bichard and Kazmierczak, 2012; Botzen et al., 2009b; Box et al., 2013; Grothmann and Reusswig, 2006) or because the public adaptation reduced their perceptions of risk and costs (Raschky and Weck-Hannemann, 2007). Finally, other variables that have been added to the PMT framework in past studies and which appear to be influential in households' risk reduction decisions are knowledge (Martin et al., 2007), flood experience (Poussin et al., 2014; Siegrist and Gutscher, 2006, 2008), public assistance (Hanger et al., 2018), and sociodemographic characteristics (e.g. Poussin et al., 2014).

In the research presented in this paper we consider the critics of the PMT-TTM framework and include some variables that previous studies did not consider. We start from the assumption that the designated shift of responsibility on flood protection from the public to the private sector implies the need to explore the current state of readiness of the public to undertake protective action. Moreover there is a need to identify good practices to inform the adoption of risk reduction behaviours. We use a framework that combines PMT with a model inspired by TTM to identify the factors that trigger individuals to protect themselves from a hazard while acknowledging different motivations among a heterogeneous public (see Sect. 3 and Fig. 3). Thus, the main research questions are the following: do different PMT variables (vulnerability, severity, benefits, self-efficacy, response efficacy, costs) affect people's behaviour to undertake risk reduction measures, and if so, does it depend on their risk reduction stage?

\section{Case study and research design}

The selected case study is the municipality of Negrar in the Veneto region, north of Verona, on the foothills of the Italian Alps (Fig. 1). The municipality ranges from 70 to $860 \mathrm{~m}$ a.s.l. and is drained by the Progno di Negrar and Progno di Novare river systems, both draining to the Adige river, which is the main river basin in the Italian part of the Eastern Alps. Whereas the northern part of the municipality is rather hillymountainous, the southern part is characterized by a valley that gets wider and actually turns into a floodplain. The structure of the municipality is further characterized by several small urban conglomerates (called frazioni). The total population of Negrar has steadily increased over the last few decades to reach a total of 17093 inhabitants in 2018. As the municipality is located in a well-known wine area in Italy, the valley is intensively cultivated. The data for this research have been collected in the frazione Arbizzano-Santa Maria (also referred to as Arbizzano, ca. 4000 inhabitants, Fig. 2).

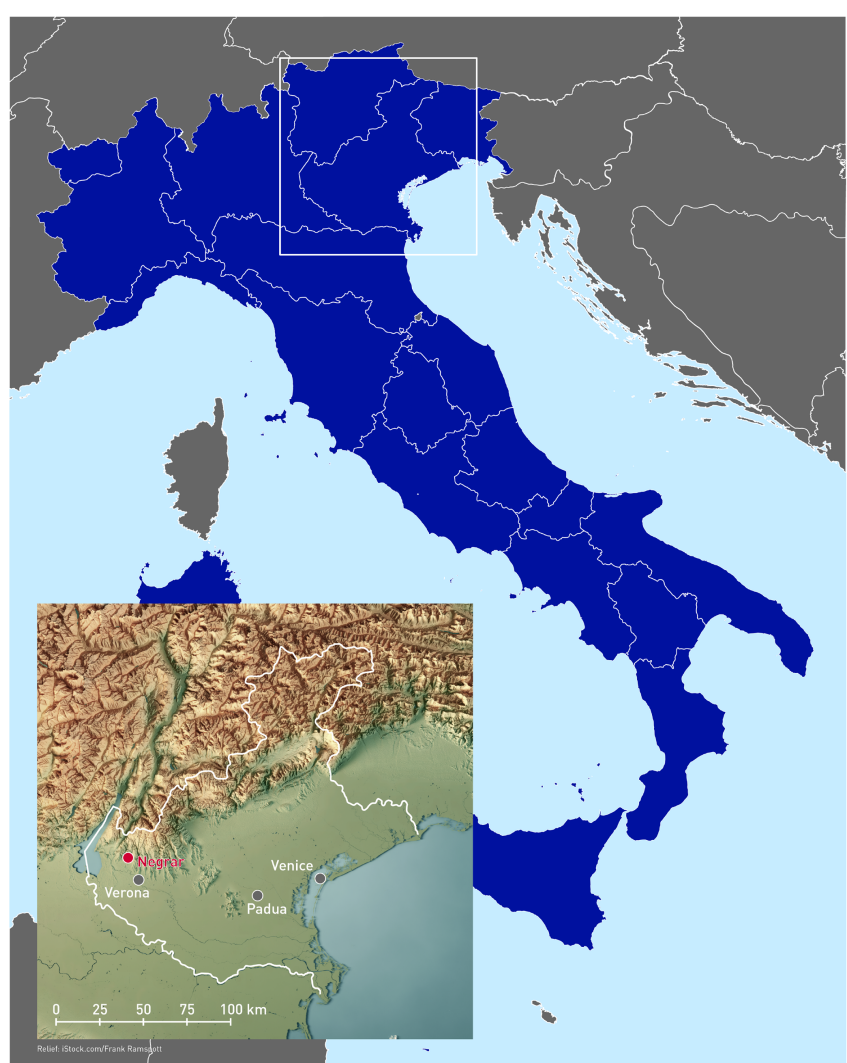

Figure 1. Map of Italy with an enlargement of the Veneto region. The three major cities Venice, Verona and Padua, as well as the study area, the municipality of Negrar, are shown on the topographic map of Veneto.

Arbizzano is located in the floodplain area in the southern part of the municipality and was especially affected by the floods. In the previous 80 years, only one flood event had occurred in the summer of 1935 and generated significant damage. The flood risk maps that are used to do the flood risk assessment in the area (called Piano di Assetto Idrogeologico dell'Adige) do not indicate any hydrological risk. This is due to the coarse resolution of these maps that are not fine enough to capture flood hazards and risks generated by small river basins such as the Novare basin $\left(2 \mathrm{~km}^{2}\right)$. These risks will be considered by novel maps, which are still in the making. Thus, flood risk communication is poor, and flood risk awareness is mainly based on historical evidence corresponding to floods which occurred in the last 80 years. Nevertheless, some people have taken risk reduction measures in the past as the level of flood risk awareness and the readiness to take these measures depends, for instance, on personal experiences (either direct or indirect) and education.

On 1 September 2018, the people living in the area experienced a severe flash flood, which impacted the upper part of the Progno di Novare river basin, with a drainage area of $2 \mathrm{~km}^{2}$ (outflow at the wine farm known as Case Bertani; see Fig. 2). With a cumulated rainfall of more than $180 \mathrm{~mm}$ in 
less than $3 \mathrm{~h}$, the event caused a very quick flood response, with a flood peak around $20 \mathrm{~m}^{3} \mathrm{~s}^{-1}$. Accumulated rain and flood peak are characterized by a return period far larger than 100 years. Hydrological data (rain and flood peak estimates) were collected and examined during a post-flood survey organized on 5 October 2018, by using the methods described by Amponsah et al. (2018). The collected data include fine-resolution weather radar data, which permitted the running of a flood simulation to cross-check the internal consistency of rain and peak flood estimates. The event caused inundations and extensive material damage, with costs of around EUR 10 million and 3000 affected people, mostly in the frazione of Arbizzano. Both new and old parts of the town were impacted by the flood. Palazzina d'Arbizzano, which is the area with the largest amount of damage, is located in the oldest part of the town. Most of the damaged houses have several (up to five) floors. Owing to the limited extent (in space and time) of the event, no (generic) flood warnings were issued, even though a threshold-based warning system is in place. Thus, no preventive measures were deployed. After the event, the Veneto region funded recovery measures with the implementation of a flood diversion system which aims to divert flood volumes from Progno di Novare to Progno di Negrar. Household protection measures were not publicly funded with this initiative; private insurance schemes are used in a very limited way in the area.

Techniques of data collection included exploration of data from existing sources, such as census data and provincial archives; interviews with local authorities to better understand the residents' risk reduction behaviours; and a questionnaire survey carried out by interviewing face-to-face a total of 146 residents in Arbizzano-Santa Maria. With regard to our sampling procedure, a context-specific methodology was required to select the respondents due to the spatial characteristics of flood hazard in the study site. The sample was drawn as to include quotas of respondents selected according to the variables age and gender so that it reflects the demographic structure of the local population. Data on the demographics were provided by the municipal administration. The municipality also provided contact persons that were affected by the flood in Arbizzano. Using snowball sampling, these people then provided us with further contacts. However, we also randomly selected households in the most affected areas in Arbizzano. This procedure was necessary to avoid the exclusion or under-representation of precisely those residents we were particularly interested in, i.e. those living in the riskiest areas. The unit of analysis was the individual, and interviewees were instructed to contact only one person per household. The interviewers read out the 28 questions included in the survey and noted the answers of the participants, who were only given a table with different risk reduction behaviours to facilitate answering some questions (see Table 1).

The data collection lasted 2 weeks from 18 February to 1 March 2019. The survey was approved by the local authorities, and the data were evaluated anonymously. Participants

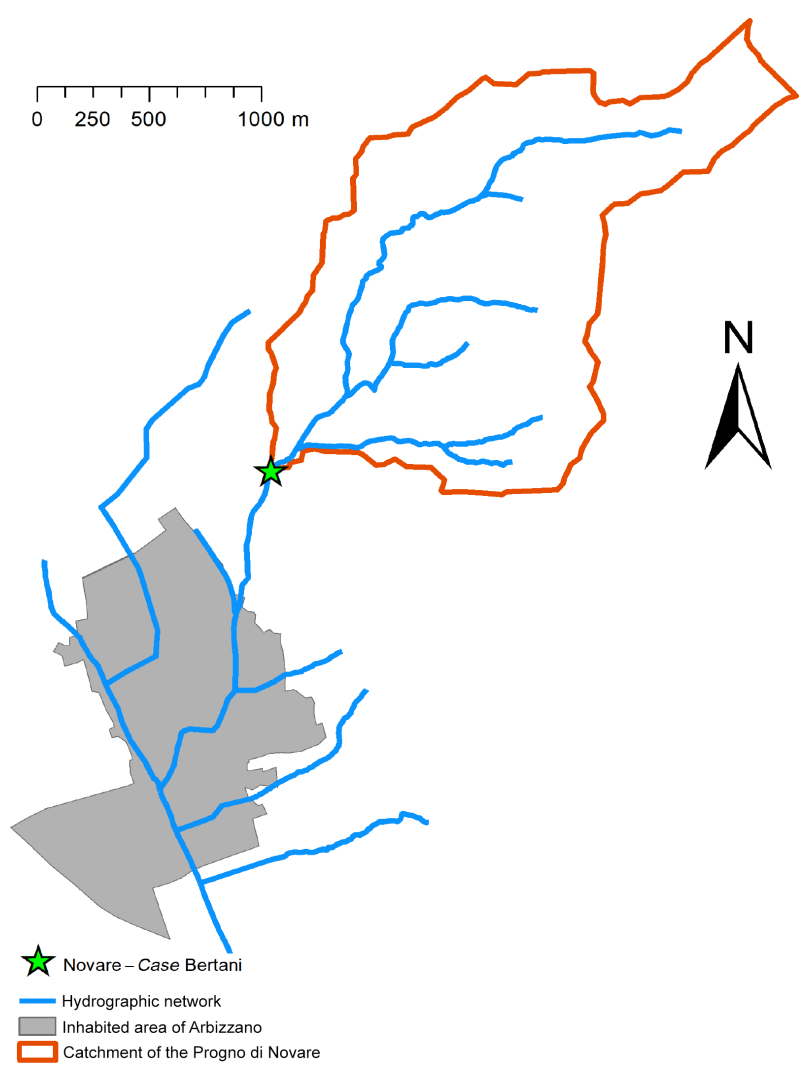

Figure 2. Map of the Progno di Novare (catchment in orange) with its outflow at Case Bertani and of Arbizzano (in grey), where most of the flash flood damage was reported.

received no incentive to complete the survey, which took them on average about $30 \mathrm{~min}$. Of the 146 residents, 17 people did not own the place they lived in and thus were excluded from data analysis. An additional 5 people were excluded during the data analysis as they did not answer some questions, leaving 124 people. Respondents ranged in age from 20 to 89 years $(M=53.38, \mathrm{SD}=17.99)$, and $77(52.7 \%)$ were female. The majority of respondents completed high school $(44.5 \%, n=65)$ followed by college or university education $(29.5 \%, n=43)$, with a further $5.5 \%$ indicating at least some compulsory education. Compared to the average population in Negrar, the sample was slightly older than the average ( $M=44.7$ years) and similar to the gender ratio of female $(50.4 \%)$ to male $(49.6 \%)$. Concerning education, people in the sample had similar levels compared to the population in the whole Veneto region.

The questionnaire was prepared on the basis of a review of the existing literature and the results of the documentary analysis, focus groups, semi-structured interviews and existing surveys (Bočkarjova et al., 2009; Hanger et al., 2018; Martin et al., 2007; Poussin et al., 2014). The responses to most of the questions were constructed on 5-point Likert scales, where 1 represented the minimum value and 5 the maximum one. The dependent variable was a composite be- 
Table 1. Overview of risk reduction behaviours.

\begin{tabular}{lll}
\hline Type of behaviour & Risk reduction behaviour & $\begin{array}{l}\text { Abbreviation } \\
\text { (referring to Fig. 4) }\end{array}$ \\
\hline Structural measures & Anti-backflow valves & S1 \\
\cline { 2 - 3 } & $\begin{array}{l}\text { Ground floor and walls made of water-resistant } \\
\text { materials }\end{array}$ & S2 \\
\cline { 2 - 3 } & $\begin{array}{l}\text { Special installation (e.g. higher up) of heating and } \\
\text { electric systems }\end{array}$ & S3 \\
\hline Avoidance measures & $\begin{array}{l}\text { Keeping personal valuables and documents out of } \\
\text { flood-prone areas of the house }\end{array}$ & A1 \\
\cline { 2 - 3 } & $\begin{array}{l}\text { Keeping expensive appliances (washing machine, } \\
\text { boiler, etc.) above expected flood levels }\end{array}$ & A2 \\
\cline { 2 - 3 } & $\begin{array}{l}\text { Adapted use of basement and ground floor } \\
\text { Mobile barriers (e.g. metal or wood shields) avail- } \\
\text { able }\end{array}$ & E1 \\
\hline $\begin{array}{l}\text { Emergency plan for household in case of floods } \\
\text { (e.g. where to go, what to take with me) }\end{array}$ & E2 \\
\hline
\end{tabular}

havioural measure. It was combined based on an average of the eight most common measures that homeowners have undertaken or will undertake to protect their properties from floods. Table 1 provides an overview of the risk reduction behaviours. These behaviours were identified by Poussin et al. (2015) and refined based on the preliminary interviews with authorities and local experts. These interviews also influenced how we operationalized the TTM. Instead of focussing on the decision stages pre-contemplative, contemplative and action and the total number of behaviours undertaken (Bočkarjova et al., 2009; Hanger et al., 2018; Martin et al., 2007; Poussin et al., 2014), we developed different risk reduction stages that focussed on the quality of behaviours planned or undertaken. We distinguished between three types of protective measures: structural, avoidance and emergency (see Table 1 and Fig. 3). Structural measures include antibackflow valves and special installation of electric and heating systems. Avoidance measures include keeping personal valuables, documents and/or expensive appliances above expected flood levels. Emergency preparedness includes the use of mobile barriers and the presence of an emergency plan. Each risk reduction behaviour was measured using a 5-point scale: (1) will never adopt the measure, (2) will maybe adopt in the long run, (3) will adopt in the near future, (4) already done before or after the flood and (0) don't know. Based on their highest-on-average scores, the respondents were divided into one of three risk reduction stages. Even though this different operationalization limited the comparability of the studies, we believed that a categorization based on the quality of measures ensures a more effective targeting of communication strategies.

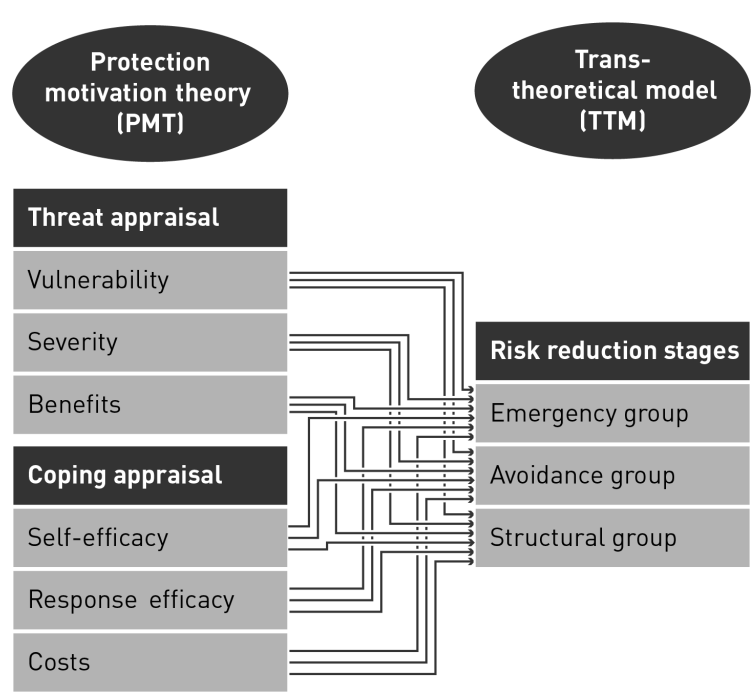

Figure 3. Dynamic protection motivation framework that builds on the protection motivation theory (PMT) and the transtheoretical model (TTM). The arrows highlight that, in each group, people are influenced by different PMT variables to engage in risk reduction behaviours.

The independent variables drew on PMT focussing on threat appraisal (vulnerability, severity, benefits) and coping appraisal (self-efficacy, response efficacy, costs; see Fig. 3). These six variables were computed based on different measures using 5-point Likert scales. We measured vulnerability by asking how much people perceived floods as a threat to their houses and themselves and severity by asking what damage they would expect from a future flood of similar 
severity to the event in September 2018. Self-efficacy was measured by asking how well-prepared people felt to face a future flood similar to the one experienced in 2018. Response efficacy was measured based on the average score of three items: structural, avoidance and emergency. People had to indicate how effective they thought the three items to be at helping to reduce the risk of floods. Costs were measured based on the time spent to implement structural, avoidance and emergency measures (three items) and the related financial costs for each of the three types of measures. Finally, benefits were measured based on the average of two items: an extrinsic reward, "I would like to take extra precautions against flooding if I am rewarded or assisted by the government", and an intrinsic reward, "Taking extra risk reduction measures against flooding is a priority". In addition, we also measured subjective knowledge, trust in government, flood experience, public assistance, having flood insurance and socio-demographic variables (age, gender, income, homeownership and education). We performed the data analysis using IBM SPSS Statistics 23, software used for statistical analysis in social science. Several regression analyses were conducted to study the effect of PMT variables in each group and overall. Other covariables were also included in more extended models. Moreover, one-way analyses of variances were conducted to study the effect of socio-demographics on the PMT variables.

\section{Results}

We first analysed respondents' answers concerning risk reduction measures. As expected, the adoption of these behaviours is quite low. Figure 4 shows the results revealing that respondents generally indicated higher likelihoods of undertaking avoidance actions (A1-A3, $M=2.06$ ) than structural measures (S1-S3, $M=1.41)$ and emergency preparedness measures (E1-E2, $M=1.56)$. Avoidance actions include storing valuables, documents or expensive appliances above expected flood levels: $24 \%$ of all homeowners had already stored valuables above flood levels before the flood in the year 2018 (and since then an additional 19.2\%), 34.9\% store valuable appliances above flood zones, and $15.7 \%$ have an adaptive use of basement (e.g. no sleeping rooms). A minority of people have installed special heating or electricity installations $(19.8 \%)$, anti-backflow valves $(17.1 \%)$ or use water-resistant materials (7.6\%). Likewise, for the emergency measures, less than $20 \%$ had mobile barriers (such as sandbags) available at home and only $11 \%$ had an emergency plan. Overall, it is important to highlight that the majority of people indicated they had implemented just a few measures.

Based on the eight risk reduction measures, we computed the composite behavioural measure from 1 (will never do) to 4 (already done, before or after the flood). Thus, the higher the score, the higher the stated behaviour to undertake protective action. Following the respondents' highest-on-average

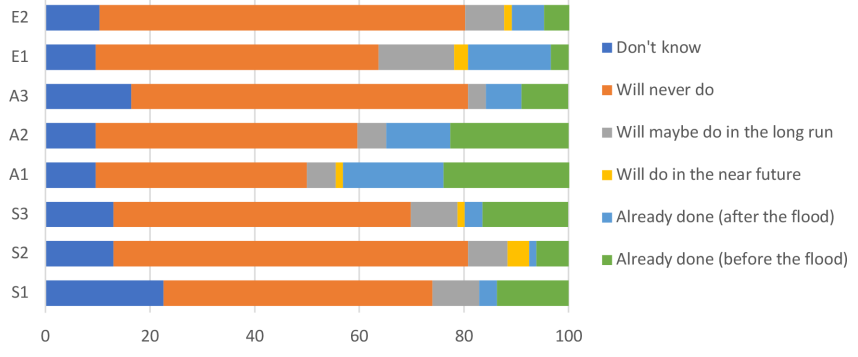

Figure 4. Results indicating the percentage of responses in each category of the Likert scale for each risk reduction measure.

scores for each type of behaviour (structural, avoidance and emergency), we further divided the respondents in our sample into three risk reduction stages: structural, avoidance and emergency. Thus, those who have already undertaken more structural measures (or are most likely to do so) compared to the avoidance and emergency measures were put into the structural group. Those who have adopted mostly, or were most likely to adopt, avoidance measures were grouped in the avoidance group, and participants with the highest scores for emergency preparedness measures were integrated into the emergency group. Thus, the 124 participants were divided into the three groups as follows: 26 in the emergency preparedness group, 53 in the avoidance group and 45 in the structural group.

We continue by analysing the influence of different PMT variables on undertaking risk reduction measures in each risk reduction stage. Table 2 shows the effects of the variables vulnerability, severity, self-efficacy, response efficacy, benefits and costs on the composite risk reduction behaviour measure for each stage. The associated descriptive statistics are provided in Table 3. The results for the first regression for the emergency group show that the only significant predictors of risk reduction behaviour are perceived severity of damage and costs. The higher the perceived damage, or the lower the perceived costs, the more likely it is that people will undertake emergency measures. In the avoidance stage, vulnerability and self-efficacy are the most important predictors. The more people considered floods to be a threat, and the more they believe to be well-prepared to face a flood, the more likely they are to adopt avoidance behaviours. The third regression highlights that the significant predictors for people in the structural group are vulnerability, severity, response efficacy and costs. People at this stage are more likely to be motivated to engage in structural risk reduction behaviours by various factors: high perceived vulnerability, response efficacy, and weak perceptions of hazard severity and costs. The overall model indicates that, independent of risk reduction stage, coping factors (self-efficacy and response efficacy) are more important than the assessment of threats in motivating people to engage in risk reduction behaviours. At the same time higher costs, both in terms of time to implement a measure and money to finance it, demotivate people to 
Table 2. Beta coefficients and $p$ values for risk reduction behaviours regressed on vulnerability, severity, self-efficacy, response efficacy, benefits and costs.

\begin{tabular}{lrrrr}
\hline & \multicolumn{3}{c}{ Risk reduction stage readiness } \\
\cline { 2 - 5 } & Emergency & Avoidance & Structural & Overall \\
\hline Vulnerability & -0.477 & $\mathbf{0 . 6 0 9}$ & $\mathbf{0 . 6 6 4}^{*}$ & 0.195 \\
Severity & $\mathbf{0 . 7 0 2}^{*}$ & -0.362 & $-0.672^{*}$ & -0.023 \\
Self-efficacy & -0.223 & $\mathbf{0 . 9 2 2}^{* *}$ & 0.181 & $0.325^{*}$ \\
Response efficacy & -0.241 & 0.253 & $\mathbf{0 . 4 5 6}^{*}$ & $0.280^{*}$ \\
Benefits & 0.021 & -0.187 & -0.008 & -0.147 \\
Costs & $-1.067^{*}$ & -0.154 & $-0.741^{* *}$ & $-0.541^{* *}$ \\
$F$ ratio & $4.331^{*}$ & $6.701^{* *}$ & $5.194^{* *}$ & $6.228^{* *}$ \\
$R^{2}$ & 0.79 & 0.73 & 0.66 & 0.42 \\
\hline
\end{tabular}

Note: $R^{2}$ represents the amount of variance in the outcome explained by the model relative to the total variance. ${ }^{*} p<0.05$ and ${ }^{* *} p<0.001$. To highlight trends in the three risk reduction stages, bold values indicate significant positive correlations and italic values indicate significant negative correlations.

engage in risk reduction behaviours. Moreover, costs seem to be more important than benefits and rewards (i.e. taking extra precautions against flooding because it is a priority for the household or only if rewarded by government). These findings have important implications for flood risk communication, which are discussed in Sect. 5.

Interestingly, the additional variables (trust, experience, knowledge, public assistance and socio-demographics) do not influence people's behaviours to act upon the risk in the extended model. Even though we find some differences with respect to PMT variables, this does not translate into a significant difference on the composite risk reduction behavioural measure. Some interesting results in this respect are that women scored significantly higher than men for the threat factors (vulnerability $(F=3.98, p=0.048)$ and severity $(F=9.43, p=0.003))$ and for response efficacy $(F=6.44, p=0.013)$, as well as lower for self-efficacy $(F=7.0, p=0.01)$.

Furthermore, we also identify specific trends that can be found for each PMT variable across the three risk reductions stages. The different fonts (italic and bold) in Table 2 help to visually summarize the key trends. For severity of expected damage, we can observe a linear trend. Severity is positively correlated with taking protective action in the group relying on emergency measures and negatively correlated in the group relying on structural measures. Vulnerability shows the exact opposite pattern. Negative (but insignificant) in the group relying on emergency measures, it becomes positive and is a significant motivator for people to undertake avoidance or structural measures. Response efficacy shows a similar trend and becomes positively correlated with risk reduction behaviour in the groups relying on structural measures. Self-efficacy plays a critical role in the avoidance group and is less important in the other groups. Overall, costs have a negative impact but are of special importance for people relying on structural measures.

\section{Discussion}

In order to better understand what motivates people to protect against flood risk, we developed a dynamic protection motivation framework. We tested it in a municipality in Northern Italy that experienced severe flash flooding in 2018, shortly before the survey was conducted. The framework proved to be useful for assessing people's perceptions of flood risk and their readiness to undertake risk reduction behaviours. Our findings add to other studies in the natural-hazards field (Bočkarjova et al., 2009; Gebrehiwot and Veen, 2015; Martin et al., 2007), in which people were grouped based on the total amount of their risk reduction behaviours. However, we decided to classify people based on the quality of these behaviours and distinguished between structural, avoidance and emergency measures. Interviews with local authorities confirmed our belief that people who have an emergency plan for their household may be motivated by different factors than people who keep expensive appliances above the expected flood levels. The motivation is again different for people who installed anti-backflow valves in their houses. Therefore, we can only compare the overall results of the few studies that applied the PMT-TTM models in the natural-hazards context and not the specific findings for each group. Independent of group membership, we confirm most of the prior findings. We support Bočkarjova et al. (2009) and Gebrehiwot and Veen (2015), who also found a negative effect of costs on risk reduction behaviours. In accordance with both studies, we also show that people with strong perceptions of response efficacy have a higher likelihood of taking risk reduction actions. Furthermore, we support Gebrehiwot and Veen (2015), who showed a positive effect of self-efficacy. However, we do not find a significant overall effect of vulnerability as the other two aforementioned studies did, which could be due to the different operationalization of the variable.

Our results suggest that people are motivated by different factors to prompt risk reduction behaviours based on their risk reduction stage. We show that PMT variables influence different groups of people in different ways. Structural and avoidance groups are more likely to be motivated by increased perceptions of vulnerability and response efficacy and are less worried by expected flood damage compared to the emergency group. Self-efficacy also plays an important role in the avoidance group, whereas perceived severity of a hazard is an important factor in the emergency group. Through all the groups, costs have a significant negative impact on risk reduction behaviours, whereas benefits do not matter at all. Independent of group membership, we confirm Poussin et al. (2014) and find that coping appraisal had a more important influence than threat appraisal. High perceptions of self-efficacy and response efficacy significantly increase the likelihood of engaging in risk reduction behaviour. We also support Wachinger et al. (2013) and show that costs are the biggest impediment to action-taking. Besides costs, other reasons may also explain the low adoption of the risk 
Table 3. Descriptive statistics of variables used in the dynamic protection motivation framework.

\begin{tabular}{lrr|rr|rr|rr|r}
\hline & \multicolumn{2}{c}{ Emergency } & \multicolumn{2}{c|}{ Avoidance } & \multicolumn{2}{c}{ Structural } & \multicolumn{2}{c}{ Overall } \\
\cline { 2 - 9 } & Mean & SD & Mean & SD & Mean & SD & Mean & SD \\
\cline { 2 - 8 } Composite behavioural measure & 1.57 & 0.48 & 1.68 & 0.49 & 1.65 & 0.66 & 1.64 & 0.55 \\
\hline Vulnerability & 3.46 & 1.37 & 3.53 & 1.46 & 2.84 & 1.31 & 3.3 & 1.44 \\
Severity & 2.42 & 1.42 & 3.43 & 1.23 & 2.71 & 1.12 & 3.16 & 1.29 \\
Self-efficacy & 2.42 & 1.21 & 2.33 & 1.16 & 2.28 & 1.16 & 2.31 & 1.15 \\
Response efficacy & 3.57 & 1.14 & 3.56 & 1.11 & 3.63 & 1.10 & 3.59 & 1.10 \\
Benefits & 4.38 & 0.95 & 4.02 & 1.15 & 3.86 & 1.05 & 4.03 & 1.10 \\
Costs & 3.23 & 0.71 & 3.24 & 0.47 & 3.45 & 0.69 & 3.31 & 0.60 \\
\hline
\end{tabular}

reduction behaviours. The majority of people indicated that they did not think that a flood similar to 2018 could have happened, and many also believed that it will not happen again anytime soon. Thus, we speculate that the non-existing flood history (e.g. low perceived risk exposure) could explain the low adoption of risk reduction behaviours before, and also the limited willingness to implement measures in the aftermath of, the disaster. Furthermore, the flood may not have been severe enough as the damage was mostly economic, and no respondents had to be relocated. As people were not compensated for the damage, they may have spent their money on recovery instead of investing in future flood preparedness. Also (fortunately), no people died or were severely injured, which may further limit the psychological impact and thus the likelihood of engaging in risk reduction behaviours. Moreover, other research observed that people do not protect themselves even though the protective behaviour would be very easy to adopt. Gissing et al. (2016) observed that motorists ignored warnings and drove into flood waters despite an obvious risk of death. The authors list numerous motivations such as underestimating or not understanding the risk, feeling invincible, and not taking the warning seriously. Hence, we have to acknowledge that each person sees and responds slightly differently to flood risk and tries to reduce the uncertainty of predicting behaviour as much as possible.

Besides the identification of factors prompting risk reduction behaviours, we also identify specific trends which help to explain the current readiness of individuals to undertake protective actions. The data show that severity plays an important role in motivating people to act upon emergency behaviours, but, as people adopt more significant protections (such as anti-backflow valves or special installations of heating and electric systems), severity acts more as an inhibitor. It seems that these people feel more protected and thus are less bothered about the severity of a hazard and its expected damage. For response efficacy the opposite is true. This indicates that, as the measures become more sophisticated, they are also perceived to be more effective in reducing or even preventing flooding. For self-efficacy, there is no trend as it is only significant in the avoidance group. This highlights that people feel ready to undertake avoidance measures on their own but less so for the structural measures, and in consequence they are not motivated by self-efficacy to engage in structural risk reduction behaviours. In this respect, it is surprising to see that self-efficacy is not significant in the emergency group as these measures (e.g. storing sandbags, having an emergency plan) could be more easily performed (like the avoidance measures). As the measures in the structural group are the most cost-intensive, costs act as an important barrier here. This could also explain why costs are no such significant barrier in the avoidance group. These measures (e.g. store valuables or boiler above the expected flood level) do not require much effort to be implemented, both in terms of financing and time. Intrinsic or extrinsic rewards (i.e. taking extra precautions against flooding because it is a priority for the household or only if rewarded by government) do not seem to be of any relevance in our sample. For instance, concerning the extrinsic reward, this could be explained by the non-existing public support after the flood and the, in general, low trust levels in the government.

We also explored a number of possible covariates, which could explain different levels of behaviour to act upon the risk. We do not find any significant influence of these variables (i.e. experience, trust and socio-demographics) on the composite risk reduction behavioural measure, but the data show an effect of gender on all PMT variables. Generally, women are more likely to engage in protective behaviour compared to men (e.g. Lazo et al., 2015; Morss et al., 2016). Previous studies also reported differences in risk perception between men and women. On average, men are found to have lower perception levels of flood risk compared to women (Ho et al., 2008; Lindell and Hwang, 2008), even though Botzen et al. (2009a) found the opposite relationship. We find that women are more threatened by the hazard and its expected damage and think measures to be more efficient than men do, and they feel less prepared to face a hazard. As this does not translate into differences in risk reduction behaviours, we speculate that it could indicate that, even though women prefer to be more protected, they do not have the decision power in the household to implement the measures. Concerning experience with floods and natural hazards, most studies found that risk perceptions and mitigation behaviours correlate with 
experience (Bubeck et al., 2012), even though some exceptions exist (Takao et al., 2004). Likewise, trust was also found by previous research to have direct and indirect effects on flood preparedness intentions (e.g. Terpstra, 2011).

Our findings draw implications for influencing individuals to perform desirable adaptive behaviours, which should help practitioners to develop better-targeted flood risk communication strategies to individuals. For people that are most likely to undertake emergency measures, increasing the perceptions of severity rather than focusing on perceptions of vulnerability will lead to greater risk reduction behaviours. The communication strategy should further try to decrease perceptions of costs and to describe benefits of the risk reduction measures. This can be done by providing extra information about flood risk and especially its consequences to these people. Moreover, storytelling can also be used as a powerful communication tool; positive and negative experiences of fellow residents that adopted and did not adopt the measures respectively can help to drive behavioural change. For the people in the avoidance group, the communication strategy should focus on the information concerning flood likelihood in the residential area and on the self-efficacy of a number of proposed flood risk reducing measures. Folders, web platforms or information events could help to raise awareness and increase flood preparedness. In the structural group, the perceptions of costs associated with taking protective action (such as time, effort and money) should be decreased. Thus, communication should stress the efficacy of structural measures in relation to the costs and give clear explanations of the effectiveness of the proposed measures. In addition, the communication should focus on information concerning flood likelihood in the area of residence and not emphasize hazard severity as it only seems to decrease the likelihood of acting upon the risk. Finally, public assistance from the government, be it financial aid for financing flood protection (e.g. subsidies, loans, tax relief) or material support (e.g. distribution of sandbags), could help overcome costs, which are the biggest impediment to, and outweigh the balance in favour of, acting.

Finally, the research was designed to analyse flood risk awareness in Italy and could therefore provide insights that are relevant for promoting the adoption of risk reduction behaviours in small municipalities in the Italian Alps. However, several case- and hazard-specific characteristics may hinder result generalization. For instance, hazards can be sloweronset, spatially diffuse (such as droughts), rapid-onset or spatially localized (such as flash floods). This clearly has relevant implications for preparedness, including for example time availability to adopt risk reduction behaviours. Furthermore, preparedness is impacted not only by the hazard characteristics but also by social, legal, cultural, institutional and political aspects that can strongly differ from one region or case to another. Thus, further research would be needed to explore these aspects, e.g. by applying the same PMT-TTM model for different hazards and in different countries.

\section{Conclusions}

In this study, we apply a protection motivation framework to understand risk reduction behaviours. We examined the motivations of people to protect themselves and their properties from flooding but did not analyse the influences of significant flood protection measures (such as the flood diversion system) separately. Overall, we observed low adoption of risk reduction behaviours in Negrar. We demonstrate that people are motivated by different factors in prompting risk reduction behaviour based on their stage readiness. Thus, property owners in flood risk areas should not be considered as a homogeneous community that can be targeted with a single communication strategy, and communication strategies should not be applied homogenously across large areas but instead should be tailored to the individual motivations to act upon a risk or not in order to be effective. However, an enabling condition to do so will be the integration of risk perception and preparedness surveys in local flood risk management practices. These surveys should be included in longitudinal studies, which may also help people to better understand the driving factors of risk reduction behaviours through time. Especially in the areas at highest risk, short surveys could be a valuable (cost- and time-efficient) instrument to find out at what risk reduction stage people are. If survey information is not available, practitioners may decide a priori the desired or most likely risk reduction measure (emergency, avoidance or structural) for a community or an area and target their communication accordingly. This means that they could then rely on the specific PMT variables identified in this study to motivate people to undertake the selected measures.

Data availability. A DOI was generated and reserved for the data: https://doi.org/10.3929/ethz-b-000337912 (Mondino et al., 2019). However, please note that the uploaded digital object will not be made available to external users until the related studies have been published.

Author contributions. PW designed the framework and developed the research questions. PW also conducted the data analysis and wrote most of the paper. EM helped design and carried out the field survey. AS helped design the survey and wrote some parts of the paper. MB established the contacts with the local administration and provided local information on the case study. GDB and AP revised the draft and provided comments and inputs.

Competing interests. The authors declare that they have no conflict of interest.

Acknowledgements. We thank the municipality of Negrar for its valuable inputs and the local administration for supporting this 
project. We also thank the students from the University of Padua who helped collect the data.

Review statement. This paper was edited by Vassiliki Kotroni and reviewed by two anonymous referees.

\section{References}

Adger, W. N., Quinn, T., Lorenzoni, I., Murphy, C., and Sweeney, J.: Changing social contracts in climatechange adaptation, Nat. Clim. Change, 3, 330-333, https://doi.org/10.1038/nclimate1751, 2013.

Amponsah, W., Ayral, P.-A., Boudevillain, B., Bouvier, C., Braud, I., Brunet, P., Delrieu, G., Didon-Lescot, J.-F., Gaume, E., Lebouc, L., Marchi, L., Marra, F., Morin, E., Nord, G., Payrastre, O., Zoccatelli, D., and Borga, M.: Integrated highresolution dataset of high-intensity European and Mediterranean flash floods, Earth Syst. Sci. Data, 10, 1783-1794, https://doi.org/10.5194/essd-10-1783-2018, 2018.

Bichard, E. and Kazmierczak, A.: Are homeowners willing to adapt to and mitigate the effects of climate change?, Climatic Change, 112, 633-654, https://doi.org/10.1007/s10584011-0257-8, 2012.

Block, L. G. and Keller, P. A.: Beyond Protection Motivation: An Integrative Theory of Health Appeals, J. Appl. Soc. Psychol., 28, 1584-1608, 1998.

Bočkarjova, M., van der Veen, A., and Geurts, P.: A PMT-TTM model of protective motivation for flood danger in the Netherlands, ITC Working Papers Series Paper 3-November, available at: http://www.itc.nl/library/papers_2009/scie/bockarjova_ pmt.pdf (last access: 3 February 2017), 2009.

Bostrom, A., Morss, R. E., Lazo, J. K., Demuth, J. L., Lazrus, H., and Hudson, R.: A Mental Models Study of Hurricane Forecast and Warning Production, Communication, and Decision-Making, Weather Clim. Soc., 8, 111-129, https://doi.org/10.1175/WCAS-D-15-0033.1, 2015.

Botzen, W. J. W., Aerts, J., and Van Den Bergh, J.: Dependence of flood risk perceptions on socioeconomic and objective risk factors, Water Resour. Res., 45, 1-15, 2009a.

Botzen, W. J. W., Aerts, J. C. J. H., and van den Bergh, J. C. J. M.: Willingness of homeowners to mitigate climate risk through insurance, Ecol. Econ., 68, 2265-2277, https://doi.org/10.1016/j.ecolecon.2009.02.019, 2009b.

Box, P., Thomalla, F., and van den Honert, R.: Flood Risk in Australia: Whose Responsibility Is It, Anyway?, Water, 5, 15801597, https://doi.org/10.3390/w5041580, 2013.

Bubeck, P., Botzen, W. J. W., and Aerts, J. C. J. H.: A Review of Risk Perceptions and Other Factors that Influence Flood Mitigation Behavior, Risk Anal., 32, 1481-1495, https://doi.org/10.1111/j.1539-6924.2011.01783.x, 2012.

Carter, J. G.: Climate change adaptation in European cities, Curr. Opin. Environ. Sustain., 3, 193-198, https://doi.org/10.1016/j.cosust.2010.12.015, 2011.

Chamlee-Wright, E. and Storr, V. H.: Expectations of government's response to disaster, Public Choice, 144, 253-274, https://doi.org/10.1007/s11127-009-9516-x, 2010.
Diakakis, M., Priskos, G., and Skordoulis, M.: Public perception of flood risk in flash flood prone areas of Eastern Mediterranean: The case of Attica Region in Greece, Int. J. Disaster Risk Reduct., 28, 404-413, https://doi.org/10.1016/j.ijdrr.2018.03.018, 2018.

European Environment Agency: Climate change, impacts and vulnerability in Europe 2016, Publication, available at: https://www.eea.europa.eu/publications/ climate-change-impacts-and-vulnerability-2016 (last access: 20 March 2018), 2017.

Figueiredo, E., Valente, S., Coelho, C., and Pinho, L.: Coping with risk: analysis on the importance of integrating social perceptions on flood risk into management mechanisms - the case of the municipality of Agueda, Portugal, J. Risk Res., 12, 581-602, 2009.

Floyd, D. L., Prentice-Dunn, S., and Rogers, R. W.: A MetaAnalysis of Research on Protection Motivation Theory, J. Appl. Soc. Psychol., 30, 407-429, https://doi.org/10.1111/j.15591816.2000.tb02323.x, 2000.

Gebrehiwot, T. and van der Veen, A.: Farmers Prone to Drought Risk: Why Some Farmers Undertake Farm-Level RiskReduction Measures While Others Not?, Environ. Manage., 55, 588-602, https://doi.org/10.1007/s00267-014-0415-7, 2015.

Gissing, A., Haynes, K., Coates, L., and Keys, C.: Motorist behaviour during the 2015 Shoalhaven floods, Aust. J. Emerg. Manag., 31, 25-30, 2016.

Grothmann, T. and Patt, A.: Adaptive capacity and human cognition: The process of individual adaptation to climate change, Global Environ. Chang., 15, 199-213, https://doi.org/10.1016/j.gloenvcha.2005.01.002, 2005.

Grothmann, T. and Reusswig, F.: People at Risk of Flooding: Why Some Residents Take Precautionary Action While Others Do Not, Nat. Hazards, 38, 101-120, https://doi.org/10.1007/s11069005-8604-6, 2006.

Guha-Sapir, D., Hoyois, P., Wallemacq, P., and Below, R.: Annual Disaster Statistical Review 2016: The numbers and trends, Centre for Research on the Epidemiology of Disasters, available at: https://reliefweb.int/report/world/ annual-disaster-statistical-review-2016-numbers-and-trends (last access: 20 March 2018), 2017.

Hanger, S., Linnerooth-Bayer, J., Surminski, S., Nenciu-Posner, C., Lorant, A., Ionescu, R., and Patt, A.: Insurance, Public Assistance, and Household Flood Risk Reduction: A Comparative Study of Austria, England, and Romania, Risk Anal., 38, 680693, https://doi.org/10.1111/risa.12881, 2018.

Ho, M.-C., Shaw, D., Lin, S., and Chiu, Y.-C.: How Do Disaster Characteristics Influence Risk Perception?, Risk Anal., 28, 635643, https://doi.org/10.1111/j.1539-6924.2008.01040.x, 2008.

Horwath, C. C.: Applying the transtheoretical model to eating behaviour change: challenges and opportunities, Nutr. Res. Rev., 12, 281-317, https://doi.org/10.1079/095442299108728965, 1999.

IPCC: Managing the Risks of Extreme Events and Disasters to Advance Climate Change Adaptation, Special Report of the Intergovernmental Panel on Climate Change, Intergovernmental Panel on Climate Change, Cambridge, UK and New York, NY, USA, available at: https://www.ipcc.ch/pdf/special-reports/srex/ SREX_Full_Report.pdf (last access: 25 January 2017), 2012.

Kellens, W., Terpstra, T., and De Maeyer, P.: Perception and Communication of Flood Risks: A Systematic Review of Empirical 
Research, Risk Anal., 33, 24-49, https://doi.org/10.1111/j.15396924.2012.01844.x, 2013.

Keller, C., Siegrist, M., and Gutscher, H.: The Role of the Affect and Availability Heuristics in Risk Communication, Risk Anal., 26, 631-639, https://doi.org/10.1111/j.1539-6924.2006.00773.x, 2006.

Kreibich, H., Thieken, A. H., Petrow, Th., Müller, M., and Merz, B.: Flood loss reduction of private households due to building precautionary measures - lessons learned from the Elbe flood in August 2002, Nat. Hazards Earth Syst. Sci., 5, 117-126, https://doi.org/10.5194/nhess-5-117-2005, 2005.

Lara, A., Saurí, D., Ribas, A., and Pavón, D.: Social perceptions of floods and flood management in a Mediterranean area (Costa Brava, Spain), Nat. Hazards Earth Syst. Sci., 10, 2081-2091, https://doi.org/10.5194/nhess-10-2081-2010, 2010.

Lazo, J. K., Bostrom, A., Morss, R. E., Demuth, J. L., and Lazrus, H.: Factors Affecting Hurricane Evacuation Intentions, Risk Anal., 35, 1837-1857, https://doi.org/10.1111/risa.12407, 2015.

Lindell, M. K. and Hwang, S. N.: Households' Perceived Personal Risk and Responses in a Multihazard Environment, Risk Anal., 28, 539-556, https://doi.org/10.1111/j.1539-6924.2008.01032.x, 2008.

Maddux, J. E. and Rogers, R. W.: Protection motivation and selfefficacy: A revised theory of fear appeals and attitude change, J. Exp. Soc. Psychol., 19, 469-479, https://doi.org/10.1016/00221031(83)90023-9, 1983.

Martens, T., Garrelts, H., Grunenberg, H., and Lange, H.: Taking the heterogeneity of citizens into account: flood risk communication in coastal cities - a case study of Bremen, Nat. Hazards Earth Syst. Sci., 9, 1931-1940, https://doi.org/10.5194/nhess-9-19312009, 2009.

Martin, I. M., Bender, H., and Raish, C.: What Motivates Individuals to Protect Themselves from Risks: The Case of Wildland Fires, Risk Anal., 27, 887-900, https://doi.org/10.1111/j.15396924.2007.00930.x, 2007.

Mondino, E., Weyrich, P., Albrecht, F., Bernello, G., Bisoffi, G., Borga, M., Bort, V., Di Baldassarre, G., Mård, J., Poli, E., Professione, F., and Scolobig, A.: A flood risk oriented dynamic protection motivation framework to explain risk reduction behaviours, https://doi.org/10.3929/ethz-b-000337912, 2019.

Morss, R. E., Demuth, J. L., Bostrom, A., Lazo, J. K., and Lazrus, H.: Flash Flood Risks and Warning Decisions: A Mental Models Study of Forecasters, Public Officials, and Media Broadcasters in Boulder, Colorado, Risk Anal., 35, 2009-2028, https://doi.org/10.1111/risa.12403, 2015.

Morss, R. E., Mulder, K. J., Lazo, J. K., and Demuth, J. L.: How do people perceive, understand, and anticipate responding to flash flood risks and warnings? Results from a public survey in Boulder, Colorado, USA, J. Hydrol. Pt. A, 541, 649-664, https://doi.org/10.1016/j.jhydrol.2015.11.047, 2016.

Munich RE: TPOICS Geo: Naturkatastrophen 2017: Ein Jahr der Stürme, Munich RE, Munich, 1-64, 2017.

Parker, D. J., Priest, S. J., and Tapsell, S. M.: Understanding and enhancing the public's behavioural response to flood warning information, Meteorol. Appl., 16, 103-114, https://doi.org/10.1002/met.119, 2009.
Poussin, J. K., Botzen, W. J. W., and Aerts, J. C. J. H.: Factors of influence on flood damage mitigation behaviour by households, Environ. Sci. Pol., 40, 69-77, https://doi.org/10.1016/j.envsci.2014.01.013, 2014.

Poussin, J. K., Wouter Botzen, W. J., and Aerts, J. C. J. H.: Effectiveness of flood damage mitigation measures: Empirical evidence from French flood disasters, Global Environ. Chang., 31, 74-84, https://doi.org/10.1016/j.gloenvcha.2014.12.007, 2015.

Prochaska, J. O., Norcross, J. C., and DiClemente, C. C.: Changing for good, Avon Books New York, available at: http://healingunleashed.com/wp-content/uploads/2014/03/ CHANGE-BOOK.pdf (last access: 3 February 2017), 1995.

Raschky, P. A. and Weck-Hannemann, H.: Charity hazard - A real hazard to natural disaster insurance?, Environ. Hazards, 7, 321329, https://doi.org/10.1016/j.envhaz.2007.09.002, 2007.

Scolobig, A., Marchi, B. D., and Borga, M.: The missing link between flood risk awareness and preparedness: findings from case studies in an Alpine Region, Nat. Hazards, 63, 499-520, https://doi.org/10.1007/s11069-012-0161-1, 2012.

Scolobig, A., Prior, T., Schröter, D., Jörin, J., and Patt, A.: Towards people-centred approaches for effective disaster risk management: Balancing rhetoric with reality, Int. J. Disaster Risk Reduct., 12, 202-212, https://doi.org/10.1016/j.ijdrr.2015.01.006, 2015.

Siegrist, M. and Gutscher, H.: Flooding Risks: A Comparison of Lay People's Perceptions and Expert's Assessments in Switzerland, Risk Anal., 26, 971-979, https://doi.org/10.1111/j.15396924.2006.00792.x, 2006.

Siegrist, M. and Gutscher, H.: Natural Hazards and Motivation for Mitigation Behavior: People Cannot Predict the Affect Evoked by a Severe Flood, Risk Anal., 28, 771-778, https://doi.org/10.1111/j.1539-6924.2008.01049.x, 2008.

Takao, K., Motoyoshi, T., Sato, T., Fukuzondo, T., Seo, K., and Ikeda, S.: Factors determining residents' preparedness for floods in modern megalopolises: the case of the Tokai flood disaster in Japan, J. Risk Res., 7, 775-787, https://doi.org/10.1080/1366987031000075996, 2004.

Terpstra, T.: Emotions, Trust, and Perceived Risk: Affective and Cognitive Routes to Flood Preparedness Behavior, Risk Anal., 31, 1658-1675, https://doi.org/10.1111/j.15396924.2011.01616.x, 2011.

Terpstra, T. and Gutteling, J. M.: Households' Perceived Responsibilities in Flood Risk Management in The Netherlands, Int. J. Water Resour. Dev., 24, 555-565, https://doi.org/10.1080/07900620801923385, 2008.

Wachinger, G., Renn, O., Begg, C., and Kuhlicke, C.: The Risk Perception Paradox - Implications for Governance and Communication of Natural Hazards, Risk Anal., 33, 1049-1065, https://doi.org/10.1111/j.1539-6924.2012.01942.x, 2013.

Weinstein, N. D.: Tage theories of health behavior: Conceptual and methodological issues, available at: http://psycnet.apa.org/ journals/hea/17/3/290/ (last access: 31 January 2017), 1998.

Zaalberg, R., Midden, C., Meijnders, A., and McCalley, T.: Prevention, Adaptation, and Threat Denial: Flooding Experiences in the Netherlands, Risk Anal., 29, 1759-1778, https://doi.org/10.1111/j.1539-6924.2009.01316.x, 2009. 